\title{
Evidence of growth hormone effect on plasma leptin in diet-induced obesity and diet-resistant rats
}

\author{
Sutharinee Likitnukul, Sarinee Kalandakanond-Thongsong, Sumpun Thammacharoen*
}

\begin{abstract}
Background: Plasma leptin is regulated by several factors, including growth hormone (GH), which influences the pathophysiology of obesity.

Objective: To demonstrate the short-term effect of GH on plasma leptin levels in 3 conditions in vivo with the different amount of body fat mass.

Methods: Adult male Wistar rats were fed with standard chow or hypercaloric diet (HC). The HC rats were demonstrated as $\mathrm{HC}$-feeding obese (HC-O) and HC-feeding resistant (HC-R) rats. Then, they were treated with $\mathrm{GH}$ or saline for 3 days. Basal plasma leptin levels were measured at 24 and 32 h. For meal-induced condition, all rats were fed for 2 hand plasma leptin was measured. Further 16-h fasting period, plasma leptin, insulin, and insulin sensitivity indexes were determined.

Results: The short-term GH treatment decreased basal plasma leptin at $32 \mathrm{~h}$ after the first GH injection in HC-O rats. However, GH treatment had no effect on meal-induced plasma leptin in all rats. Furthermore, GH treatment attenuated fasting effect on plasma leptin in control and HC-R rats. The insulin resistance (IR) induced by the short-term GH treatment was demonstrated by higher fasting plasma insulin and the increased homeostasis model of IR in HC-R rats. Conclusions: The study demonstrates the important role of greater fat mass in HC-O rats, which results in decreased basal plasma leptin after short-term GH treatment. For meal-induced condition, GH had no effect on plasma leptin in all rats. Interestingly, GH could attenuate fasting effect on plasma leptin in rats that have lower fat mass.
\end{abstract}

Keywords: adipose tissue; growth hormone; insulin resistance; leptin; obesity

White adipose tissue is considered the major leptin-secreting organ. The mechanisms regulating leptin production and secretion are complex and depend on multiple factors. Plasma leptin is well correlated with fat mass in both lean and obese animals $[1,2]$. Plasma leptin and its pattern have been investigated in many animals, including laboratory rodents and humans [3-5]. In adult rats, plasma leptin shows basal level without peak in light period [4, 6-7]. This plasma leptin level could be influenced mainly by nutritional status (i.e., feeding and fasting), glucose and free fatty acids (FFAs), and hormonal control (i.e., insulin and catecholamines). Feeding and fasting models suggested important roles of plasma insulin,

*Correspondence to: Sumpun Thammacharoen, Department of Veterinary Physiology, Faculty of Veterinary Science, Chulalongkorn University, Bangkok 10330, Thailand, e-mail: Sumpun.P@chula.ac.th

Department of Veterinary Physiology, Faculty of Veterinary Science, Chulalongkorn University, Bangkok 10330, Thailand

OOpen Access. ( 2018 Likitnukul et al., published by Sciendo. (c) BY-NC-ND This work is licensed under the Creative Commons Attribution NonCommercial-NoDerivatives 4.0 License. 
glucose, and FFA in the diurnal patterns of plasma leptin $[3,4,8-10]$. In addition to these well-known effects of insulin on plasma leptin, growth hormone $(\mathrm{GH})$ has also been demonstrated to influence plasma leptin [11-15]. With longterm GH treatment, lower plasma leptin has been demonstrated in accordance with decreased fat mass $[16,17]$. This article aimed to study the short-term GH effect on plasma leptin, which was independently of the altered body adiposity. This point was interesting for 3 main reasons. First, obesity is associated with attenuated plasma $\mathrm{GH}$, in which $\mathrm{GH}$ has long been considered as hormonal treatment in obesity and metabolic syndrome [18-20]. Second, short-term GH treatment decreased food intake (FI) in laboratory rodents and goats $[14,15]$, which may associate with elevated plasma leptin in this period. Finally, the metabolic effects of GH are closely related to and influenced by insulin and leptin [21]. The latter argument appeared to be the major cause of the discrepancy in the short-term GH treatment on plasma leptin [11-15]. To study whether fat mass influenced the effect of $\mathrm{GH}$ on plasma leptin, the current experiments investigated the short-term effects of GH treatment on 2 different amounts of adipose tissue mass from control and obese rats. In addition, this study emphasized basal plasma leptin, which refers to the light phase plasma leptin in ad libitum rats [4], meal-induced and fasting conditions. The information from the current studies would contribute to the fundamental mechanisms of leptin secretion from adipose tissue and perhaps support the idea of GH as an adjunct, but not main, hormonal treatment in obesity.

\section{Materials and methods}

\section{Animals}

Adult male Wistar rats, aged 12 weeks, were purchased from National Laboratory Animal Center, Mahidol University, and individually housed in conventional hanging cages with stainless steel wire mesh floors $(33 \mathrm{~cm} \times 18 \mathrm{~cm} \times 20 \mathrm{~cm})$ under standard condition $\left(12 \mathrm{~h} / 12 \mathrm{~h}\right.$ light/dark cycle, $\left.22 \pm 1^{\circ} \mathrm{C}\right)$. All rats were allowed to acclimatize to the experimental condition for at least 2 weeks before starting the experiment. The rats were fed standard diet rat chow (\#082; Perfect Companion Group Ltd., Samutprakarn, Thailand; protein 24\%, carbohydrate $42 \%$, fat $4.5 \%$, energy $3.04 \mathrm{kcal} / \mathrm{g}$, energy from fat $13 \%$ ) and water ad libitum. During the 6 weeks of obesity induction, rats were randomly divided into 2 groups and fed with either standard diet rat chow (control) or hypercaloric diet (HC; protein $17.52 \%$, carbohydrate $30.66 \%$, fat $30.3 \%$, energy $4.65 \mathrm{kcal} / \mathrm{g}$, energy from fat $60 \%$ ). At the end of this period, $\mathrm{HC}$ obese (HC-O) rats were separated from $\mathrm{HC}$ resistant (HC-R) rats at the lowest tertile of body weight (BW) gain. The HC-R rats were the $\mathrm{HC}$-fed rats that gained less weight than $\mathrm{HC}-\mathrm{O}$ rats and used as diet control rats for $\mathrm{HC}$ feeding. The characteristics of the control, $\mathrm{HC}-\mathrm{R}$, and $\mathrm{HC}-\mathrm{O}$ rats are presented in Table 1. BW and FI (23 h FI, $\pm 0.1 \mathrm{~g}$ corrected for spillage) were recorded every day during the experimental period. All procedures conducted on animals were approved by the Institutional Animal Care and Use Committee (IACUC), Faculty of Veterinary Science, Chulalongkorn University (approval no. 1531026).

\section{Experimental procedure}

This experiment aimed at determining the effect of short-term exogenous $\mathrm{GH}$ treatment on basal, meal-induced and fasting plasma leptin in control $(\mathrm{n}=12)$ and HC-R $(\mathrm{n}=9)$ and HC-O rats $(n=12)$. All rats from each group were randomly divided into 2 subgroups and treated with either normal saline or $\mathrm{GH}$ injection ( $\mathrm{n}=6$; for control and HC-O rats, $\mathrm{n}=4$ and 5; for saline-treated and GH-treated HC-R rats, respectively). The GH-treated rats were injected subcutaneously with recombinant human GH (GenHeal ${ }^{\circledR}$; Shanghai United Cell Biotechnology Co., Ltd., Shanghai, China) $1 \mathrm{mg} / \mathrm{kg}$ twice per day (at 0800 and $1600 \mathrm{~h}$ ) for 3 days. The 3-day GH treatment was selected based on the effect of GH on basal plasma leptin from our pilot study. Blood sample $(0.3 \mathrm{~mL})$ was collected from the ventral tail artery at 24 and $32 \mathrm{~h}$ after the first $\mathrm{GH}$ injection for basal plasma leptin measurement, because the results from our pilot study indicated that GH decreased basal plasma leptin at 32-36 h under light period. Meal-induced plasma leptin was

Table 1. Characteristics of the control, HC-R, and HC-O rats in the current experiments

\begin{tabular}{lrrr}
\hline & Control $(\mathbf{n}=12)$ & HC-R $(\mathbf{n}=9)$ & HC-O $(\mathbf{n}=12)$ \\
\hline Initial BW (g) & $441.02 \pm 2.93^{\mathrm{a}}$ & $420.19 \pm 7.58^{\mathrm{b}}$ & $447.33 \pm 5.40^{\mathrm{a}}$ \\
Final BW (g) & $503.68 \pm 3.41^{\mathrm{b}}$ & $508.27 \pm 7.73^{\mathrm{b}}$ & $574.52 \pm 7.98^{\mathrm{a}}$ \\
BW gain (g) & $62.67 \pm 1.93^{\mathrm{c}}$ & $88.08 \pm 4.68^{\mathrm{b}}$ & $127.19 \pm 5.80^{\mathrm{a}}$ \\
BW gain/day & $1.57 \pm 0.05^{\mathrm{c}}$ & $2.20 \pm 0.12^{\mathrm{b}}$ & $3.18 \pm 0.14^{\mathrm{a}}$ \\
(g/day) & & & \\
Body fat mass (\%) & $11.25 \pm 0.30^{\mathrm{c}}$ & $12.92 \pm 0.41^{\mathrm{b}}$ & $14.97 \pm 0.31^{\mathrm{a}}$ \\
AUC-IPGTT & $24667 \pm 1303^{\mathrm{b}}$ & $24304 \pm 1198^{\mathrm{b}}$ & $28411 \pm 1242^{\mathrm{a}}$ \\
\hline
\end{tabular}

a-cSignificant difference between groups, $P<0.05$

AUC-IPGTT, area under the curve from intraperitoneal glucose tolerance test; BW, body weight; $\mathrm{HC}-\mathrm{O}$, hypercaloric diet obese; $\mathrm{HC}-\mathrm{R}$, hypercaloric diet resistance 
investigated at the beginning of dark phase on day 3 after the first GH injection. Rats were fasted for $2 \mathrm{~h}(1600 \mathrm{~h})$ before dark onset. At the onset of dark phase $(1800 \mathrm{~h})$, food was provided; then, the rats were allowed to access the food for $2 \mathrm{~h}$ [20]. Blood samples $(0.3 \mathrm{~mL})$ for meal-induced plasma leptin were collected before light off (premeal, $1800 \mathrm{~h}$ ), which was considered as basal leptin after $32 \mathrm{~h}$ from the first injection and after eating for $2 \mathrm{~h}$ (post-meal, $2000 \mathrm{~h}$ ). Meal-induced plasma leptin was calculated from the post- and premeal difference of plasma leptin (leptin difference). After meal-induced plasma leptin experiment, food was removed, and then the rats were fasted for another $16 \mathrm{~h}$. At the mid-light phase of day 3, blood samples were collected for the measurement of fasting plasma glucose $\left(\mathrm{G}_{\text {fasting }}\right)$, insulin $\left(\mathrm{I}_{\text {fasting }}\right), \mathrm{FFA}_{\text {fasting }}$, and leptin, as shown in Figure 1. All blood samples were centrifuged at $3,000 \mathrm{~g}$ for $15 \mathrm{~min}$ and stored at $-20^{\circ} \mathrm{C}$ for further analysis. The effect of fasting on plasma leptin was calculated from the difference between average basal plasma leptin (from 24 and $32 \mathrm{~h}$ after the first injection) and fasting plasma leptin (leptin difference). Insulin sensitivity index was calculated from plasma insulin and glucose during fasting. In addition, the surrogate indexes for insulin receptor sensitivity were calculated in the present experiment. The homeostasis model of insulin resistance (HOMA-IR $\left.=\left[\mathrm{I}_{\text {fasting }} \times \mathrm{G}_{\text {fasting }}\right] / 2,430\right)$ was used to estimate the hepatic insulin sensitivity [22]. Furthermore, the adipose tissue insulin resistance (Adipo-IR = $I_{\text {fasting }} \times \mathrm{FFA}_{\text {fasting }}$ ) was also used to estimate the adipose tissue insulin sensitivity [23]. At the end of the experiment, all rats were euthanized with intraperitoneal pentobarbital (150 mg/kg, Nembutal ${ }^{\mathbb{}}$; Ceva Sante Animale, Libourne, France). The visceral and subcutaneous fat masses were dissected to determine the total body fat mass. Leptin secretion per body fat mass was calculated from the ratio between average basal plasma leptin (from 24 and $32 \mathrm{~h}$ after the first injection) and total body fat mass.

\section{Intraperitoneal glucose tolerance test}

Glucose tolerance test was used to determine the representative whole-body insulin sensitivity after obesity induction period. The rats were fasted for $16 \mathrm{~h}$ before intraperitoneal glucose tolerance test (IPGTT) evaluation. Blood samples were collected by tail-clipping technique for blood glucose measurement (Accu-Chek ${ }^{\circledR}$ Performa; Roche Diagnostic $\mathrm{GmbH}$, Mannheim, Germany) before glucose administration (time 0). The $50 \%$ glucose solution (A.N.B. Laboratories Co., Ltd., Bangkok, Thailand) was injected intraperitoneally (2 g/kg BW). Blood glucose was measured at 15, 30, 60, 90, and 120 min after glucose injection.

\section{Plasma hormone and FFA analyses}

Plasma leptin levels were measured by ELISA kits (EZRL83K; Merck Millipore, Massachusetts, USA). The intraassay coefficient of variability (CV) for this measurement was $3.46 \%$, and the inter-assay CV was $6.97 \%$. Plasma insulin was measured with a commercial ELISA kit (EZRMI-13K; Merck Millipore, Massachusetts, USA). The intra-assay $\mathrm{CV}$ for this measurement was $2.43 \%$. Plasma FFA was measured with colorimetric assay kit (ab65341; Abcam, Cambridge, UK).

\section{GH/Saline • Blood collection}

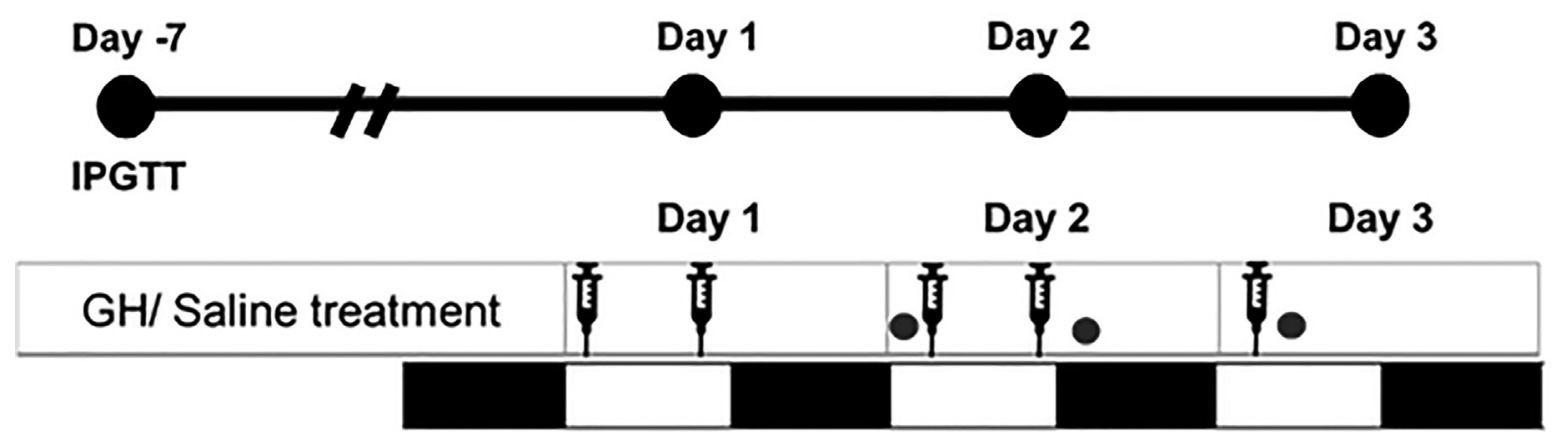

Figure 1. The experimental procedure is demonstrated. After the obesity induction period, IPGTT was performed before GH or saline treatment (at day -7 ). Then, the rats were injected with either GH or saline for 3 days and blood samples were collected for plasma hormones and FFA measurement. The white and black bars indicate light and dark phases, respectively (12h/12h light/dark cycle).

FFA, free fatty acid; GH, growth hormone; IPGTT, intraperitoneal glucose tolerance test 


\section{Statistical analyses}

The results were analyzed by 2-way analysis of variance (ANOVA). In addition, for the analysis of basal plasma leptin at 2 different time points either saline or $\mathrm{GH}$, the test was performed by 2-way repeated-measures ANOVA. The significant main effects were followed up using a Bonferroni posttest. A significant mean difference was set at $P<0.05$. All data are presented as mean \pm standard error of the mean (SEM). All the data were analyzed using GraphPad Prism 7.00 (GraphPad Software, California, USA).

\section{Results}

After 24 and $32 \mathrm{~h}$ of the first $\mathrm{GH}$ injection, Basal plasma leptin levels were not significantly different in control rats $(P>0.05$; Table 2). In addition, there was no significant effect of GH $(P>0.05)$. In HC-R rats, there was no effect of time points (24 and $32 \mathrm{~h}$ ) and $\mathrm{GH}$ on basal plasma leptin levels $(P>0.05)$. However, basal plasma leptin levels were significantly different between 24 and $32 \mathrm{~h}$ in both saline and GH-treated HC-O rats $(P<0.05)$. Basal plasma leptin level at $32 \mathrm{~h}$ was higher than that of $24 \mathrm{~h}$ in both saline and GH-treated HC-O rats $(P<0.05)$. Furthermore, the short-term GH administration had no effect on body adiposity $(P>0.05$; Figure 2A, ), while $\mathrm{HC}-\mathrm{O}$ rats had the greatest fat mass among these 3 groups $(P<0.001)$. For the normalized basal plasma leptin to total adipose mass, GH treatment decreased leptin per fat tissue $(P<0.05$; Figure 2B); this effect was demonstrated only in HC-O rats $(P<0.05)$, except control and HC-R rats $(P>0.05)$. The increased plasma leptin after meal-induced

Table 2. The effect of short-term GH treatment on basal plasma leptin at 24 and $32 \mathrm{~h}$ after $\mathrm{GH}$ injection

\begin{tabular}{lccc}
\hline \multirow{2}{*}{$\begin{array}{l}\text { Time after the first } \\
\text { injection }\end{array}$} & \multicolumn{3}{c}{ Basal plasma leptin $(\mathbf{n g} / \mathbf{m L})$} \\
\cline { 2 - 4 } & Control & HC-R & HC-O \\
\hline Saline & & & \\
$24 \mathrm{~h}$ & $16.98 \pm 0.7$ & $18.93 \pm 2.7$ & $21.16 \pm 1.0$ \\
$32 \mathrm{~h}$ & $17.94 \pm 1.2$ & $18.47 \pm 1.9$ & $29.20 \pm 1.8^{*}$ \\
$\mathrm{GH}$ & & & \\
$24 \mathrm{~h}$ & & & \\
$32 \mathrm{~h}$ & $16.89 \pm 0.8$ & $15.74 \pm 0.9$ & $17.00 \pm 1.8$ \\
\hline
\end{tabular}

*Effect of time on basal plasma leptin in HC-O rats, $P<0.05$

"Effect of GH on basal plasma leptin in saline vs GH treatment at $32 \mathrm{~h}$, $P<0.05$

$\mathrm{GH}$, growth hormone; $\mathrm{HC}-\mathrm{O}$, hypercaloric diet obese; HC-R, hypercaloric diet resistance condition was shown as leptin difference. There were no significantly different between groups and no significantly different of GH effect in each group $(P>0.05$; Figure 3A). In addition, the energy intake during $2 \mathrm{~h}$ was analyzed in all groups. The energy intake in $\mathrm{HC}-\mathrm{O}$ rats was significantly higher than that of both control and HC-R rats $(P<0.05$; Figure 3B).

In 16-h fasting condition, fasting effect on plasma leptin level was shown as leptin difference. The effect of GH on the fasting effect on plasma leptin was significantly difference $(P<0.05$; Figure 4).GH attenuated fasting effect on plasma leptin as shown in figure $4(P<0.05)$, but not in HC-O rats $(P>0.05)$. Moreover, $\mathrm{GH}$ treatment increased fasting plasma insulin in all rats $(P<0.05)$, but there were no significant effects on fasting plasma glucose and FFA in all rats $(P>0.05$; Table 3). The calculated HOMA-IR of the GH-treated group was higher than that of the saline-treated group $(P<0.05)$. The effect of GH was pronounced only in HC-R rats $(P<0.05)$ but not in control and HC-O rats $(P>0.05$; Figure 5A). In addition, the calculated Adipo-IR from saline-treated group was statistically significantly different from the GH-treated group in HC-R rats $(P<0.05)$, but not in control and HC-O rats $(P>0.05$; Figure 5B).

\section{Discussion}

Our data showed that the short-term GH treatment decreased basal plasma leptin only in $\mathrm{HC}-\mathrm{O}$ rats, which suggested that the short-term $\mathrm{GH}$ effect on basal plasma leptin partly depends on body adiposity. The results revealed that the short-term $\mathrm{GH}$ administration could not alter adipose tissue mass in all rats. Interestingly, $\mathrm{GH}$ decreased normalized plasma leptin to body fat mass only in HC-O rats. However, the short-term GH treatment could not influence meal-induced plasma leptin in all rats. In addition, $\mathrm{GH}$ administration could attenuate fasting effect on plasma leptin in the control and HC-R groups.

The main objective of the current experiment was to investigate the short-term effect of GH treatment on plasma leptin in different paradigms. By using $\mathrm{GH}$ as exogenous hormonal stimulus, the current findings revealed the different mechanisms controlling basal plasma leptin. In the current experiment, we measured basal plasma leptin during light period. After $24 \mathrm{~h}$ of the first injection, GH had no effect on basal plasma leptin. However, after $32 \mathrm{~h}$ of the first injection, plasma leptin from $\mathrm{GH}$ treatment was lower than that from saline injection in the HC-O group. It should be noted that all rats cannot access to food for $1 \mathrm{~h}$ before light off during the maintenance period every day. Since all rats were fasted for only $2 \mathrm{~h}$ before the light off (at $32 \mathrm{~h}$ after the first injection), the premeal plasma 

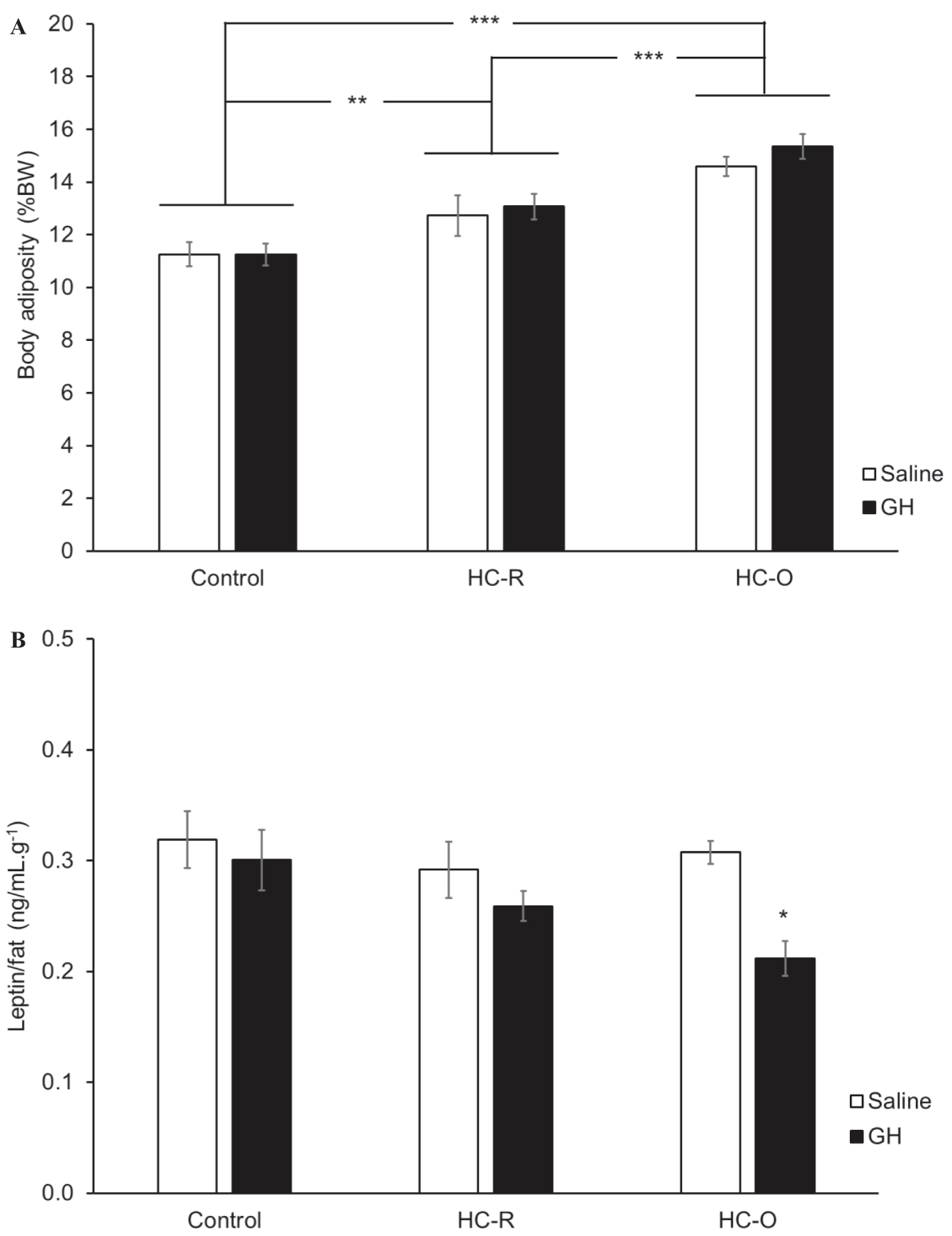

Figure 2. The effect of short-term GH treatment on body adiposity and leptin per fat mass. (A) There was no effect of GH on body adiposity in all rats, and HC-O rats had the highest fat mass compared to HC-R and control rats ( $\left.{ }^{* * *} P<0.001,{ }^{* *} P<0.01\right)$. (B) There was a significant effect of GH on leptin secretion per fat mass in $\mathrm{HC}-\mathrm{O}$ rats.

*The leptin per fat mass of GH-treated $\mathrm{HC}-\mathrm{O}$ rats was significantly lower than that from saline treatment, $P<0.05$

$\mathrm{GH}$, growth hormone; HC-O, hypercaloric diet obese; HC-R, hypercaloric diet resistance

leptin level is considered to be within the range of basal plasma leptin [3, 4]. This interpretation agrees with our pilot study for the $\mathrm{GH}$ effect on basal plasma leptin. Our results are consistent with the chronological study of acute GH treatment on basal plasma leptin in healthy humans [12]. Unfortunately, many experiments in rodents were investigated for long-term GH effect on plasma leptin or cross-sectional information [11, $25,26]$. This study suggests that the amount of adipose tissue apparently influences the effect of GH on basal plasma leptin. The previous studies demonstrated that leptin content and secretion rate have been correlated well with the fat mass and the size of adipocyte $[27,28]$. However, the reason that GH decreased basal plasma leptin levels and normalized plasma leptin to body fat mass in which specifically occurred in $\mathrm{HC}-\mathrm{O}$ rats remains unknown (see the following section). In rodents, the diurnal pattern of plasma leptin has been well demonstrated. Plasma leptin is maintained at its basal level during the light phase and gradually increases after the first meal of dark onset $[3,4]$. The reason that explained the higher plasma leptin at $32 \mathrm{~h}$ than that of $24 \mathrm{~h}$ in $\mathrm{HC}-\mathrm{O}$ rats was unknown. Although many experiments have been performed to study nighttime plasma leptin, the mechanisms that control basal plasma leptin 
A

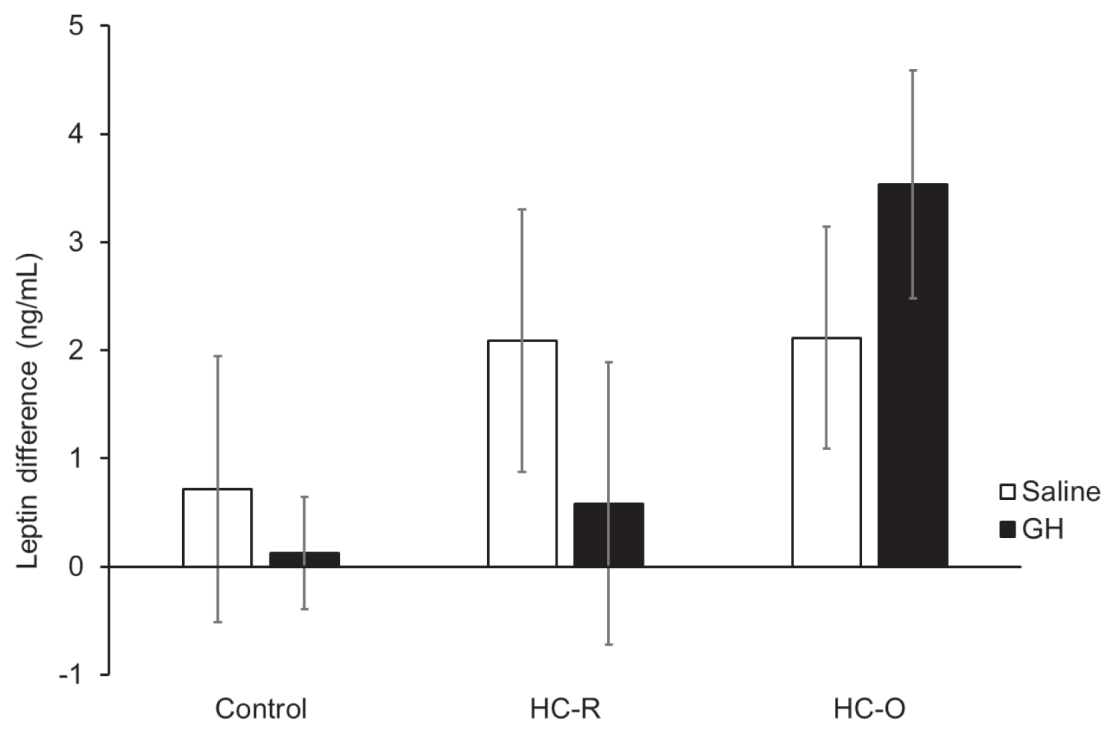

B

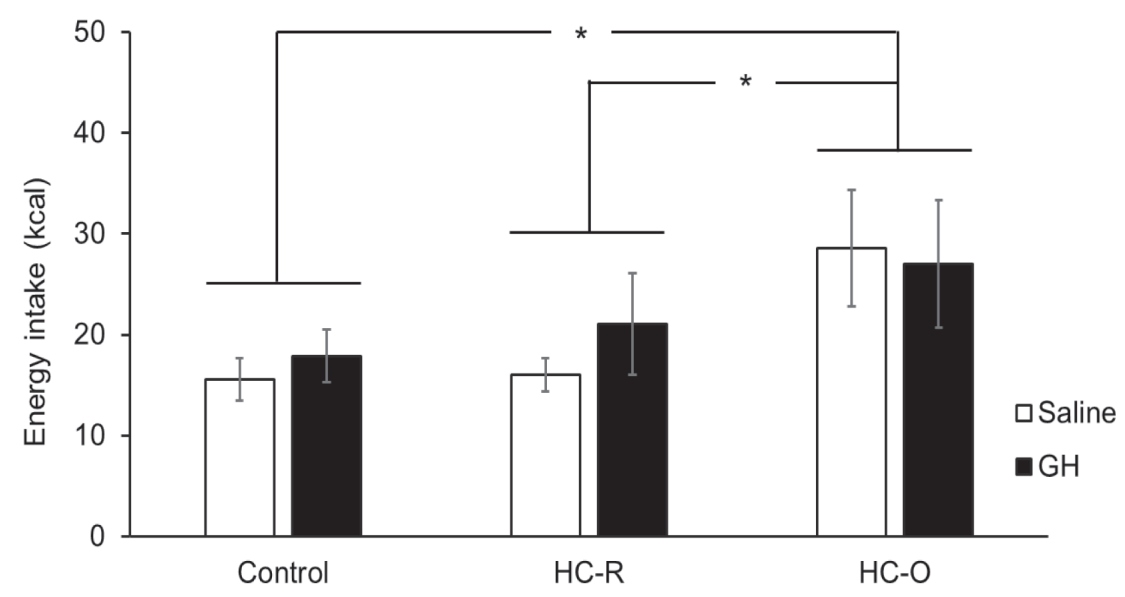

Figure 3. The effect of short-term GH treatment on meal-induced plasma leptin. (A) There was no effect of GH on meal-induced plasma leptin, which was demonstrated as leptin difference of pre- and post-meal plasma leptin. (B) The energy intake from meal-induced plasma leptin experiment revealed that $\mathrm{HC}-\mathrm{O}$ rats had the highest energy intake compared to control and $\mathrm{HC}-\mathrm{R}$ rats.

*The energy intake of $\mathrm{HC}-\mathrm{O}$ rats was significantly different from others, $P<0.05$

$\mathrm{GH}$, growth hormone; HC-O, hypercaloric diet obese; HC-R, hypercaloric diet resistance

are less studied and remain unclear. Previous studies demonstrated that basal leptin content in adipose tissue depends on new leptin synthesis. The pathway of leptin biosynthesis was apparently regulated by a mechanism independent of insulin action [29]. Taken together, the in vivo effect of GH to decrease basal plasma leptin may be mediated by decreasing the leptin content and this action may apparently be regulated by insulin-independent pathway.

Next, we demonstrated that the short-term GH treatment had no effect on meal-induced plasma leptin in all rats. Mealinduced plasma leptin has been well studied and was related to the nighttime plasma leptin in the rodent. The single peak of nighttime plasma leptin in rodents could be influenced strongly by eating behavior $[3,4]$. When food was provided only in the light phase, diurnal rhythm of plasma leptin was reversed according to eating activity [4]. Insulin and glucose were important determinants of meal-induced plasma leptin $[28,30]$. For instance, plasma leptin after glucose administration was dependent on high plasma insulin [30]. We propose from our previous result that the mechanism of GH effect on basal plasma leptin may be independent on insulin-mediated plasma leptin. The current results support, but not prove, our hypothesis and further inform that GH treatment had no effect on meal-induced plasma leptin (or insulin-stimulating leptin secretion) in $\mathrm{HC}-\mathrm{O}$ rats during the stage of ample energy. The previous report provided an association between the amount of energy intake and meal-induced plasma leptin [22]. In addition, our results revealed that $\mathrm{HC}-\mathrm{O}$ rats had the greatest 


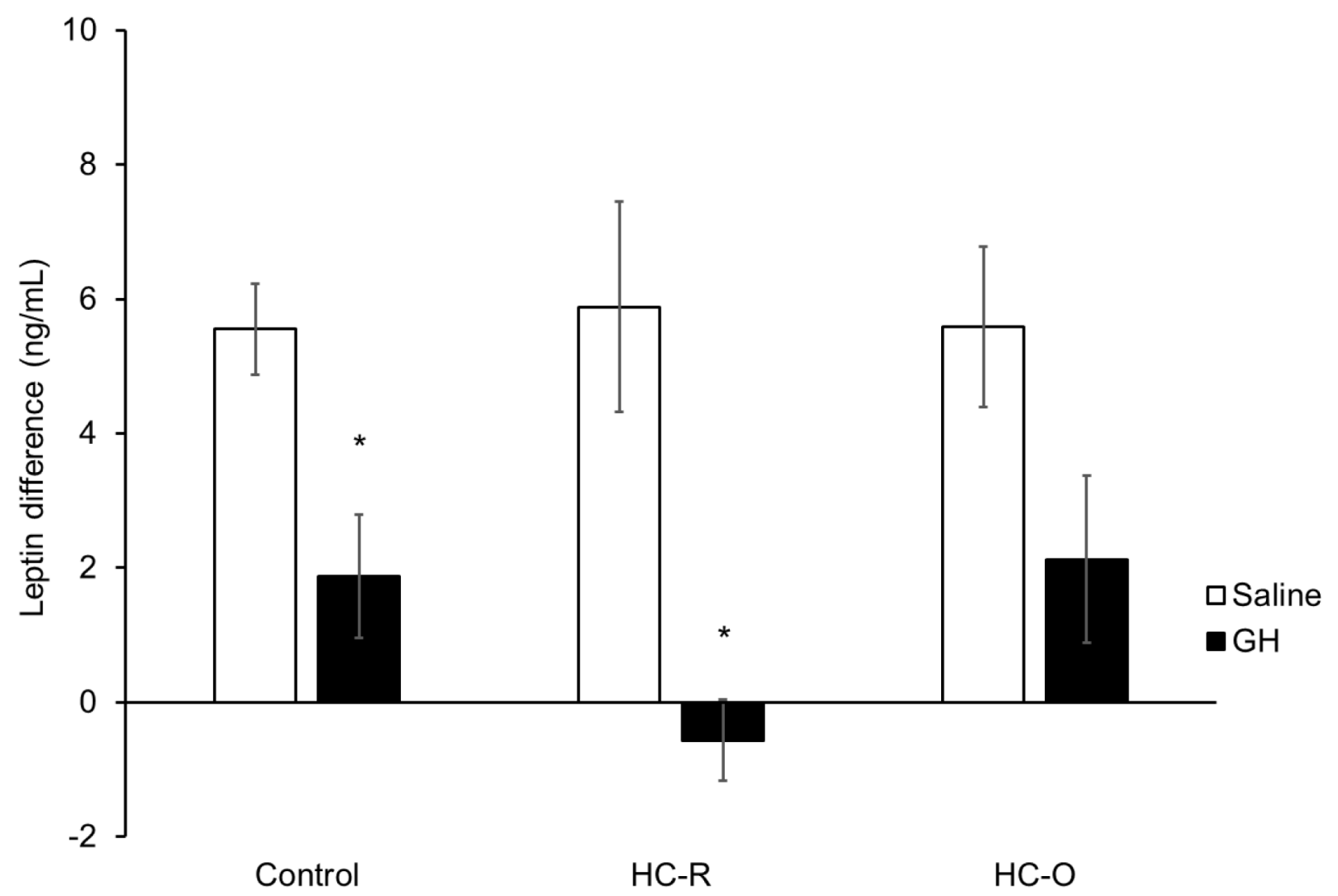

Figure 4. The effect of short-term GH treatment on the fasting effect on plasma leptin (leptin difference). There was a significant difference of the effect of GH treatment in the control and HC-R groups.

${ }^{*} \mathrm{GH}$ effect is significantly different from saline treatment, $P<0.05$.

$\mathrm{GH}$, growth hormone; HC-R, hypercaloric diet resistance

Table 3. The effect of short-term GH treatment on fasting plasma insulin, glucose, and FFA

\begin{tabular}{lccc}
\hline & Control & HC-R & HC-O \\
\hline Insulin (ng/mL) & & & \\
$\quad$ Saline & $2.96 \pm 0.5$ & $2.39 \pm 0.7$ & $5.12 \pm 0.8$ \\
GH & $6.09 \pm 1.0^{\dagger}$ & $6.26 \pm 1.4^{\dagger}$ & $6.92 \pm 1.2^{\dagger}$ \\
Glucose (mg/dL) & & & \\
$\quad$ Saline & $131.50 \pm 6.8$ & $126.00 \pm 6.0$ & $131.50 \pm 4.0$ \\
GH & $135.20 \pm 3.0$ & $126.80 \pm 12.8$ & $123.30 \pm 7.7$ \\
FFA (mmol/L) & & & \\
$\quad$ Saline & $0.55 \pm 0.13$ & $0.29 \pm 0.06$ & $0.60 \pm 0.14$ \\
GH & $0.45 \pm 0.10$ & $0.81 \pm 0.12$ & $0.67 \pm 0.17$ \\
\hline
\end{tabular}

${ }^{\dagger} \mathrm{GH}$ effect on fasting plasma insulin in all groups, $P<0.05$

FFA, free fatty acid; $\mathrm{GH}$, growth hormone; $\mathrm{HC}-\mathrm{O}$, hypercaloric diet obese; $\mathrm{HC}-\mathrm{R}$, hypercaloric diet resistance

energy intake among all groups, which was related to mealinduced plasma leptin.

Fasting plasma leptin appears to share a similar mechanism with basal and meal-induced plasma leptin. First, the leptin secretion during fasting derived mainly from the basal pool of leptin vesicle [29]. Second, decreased plasma leptin during fasting apparently occurred in part from the absence of the signal from insulin-stimulating leptin secretion [30, 31]. During fasting, decreased plasma insulin concentration as well as decreased glucose uptake and adipose tissue oxidation have been well demonstrated $[32,33]$. In addition, lipolysis is the main biochemical pathway in adipocytes to provide FFA as an energy source [34]. Although intracellular FFA has been demonstrated to attenuate insulin-stimulated leptin secretion [8], the mechanism apparently fits the stage of ample energy with the presence of insulin and glucose rather than the stage of fasting [8, 29, 31]. With 16-h fasting condition, plasma leptin was decreased in saline-treated control and HC-R rats, which was significantly different from GH-treated control and HC-R rats. This result was apparently due to the GH effect, which could attenuate fasting effect. This attenuation effect may be explained indirectly by the effect of $\mathrm{GH}$ on plasma insulin. However, for HC-O rats, the fasting effect was similar as control rats but not statistical significance $(P=0.067)$. The result suggested that adipose mass in HC-O rats may influence fasting effect on plasma leptin. We also demonstrated that 
A

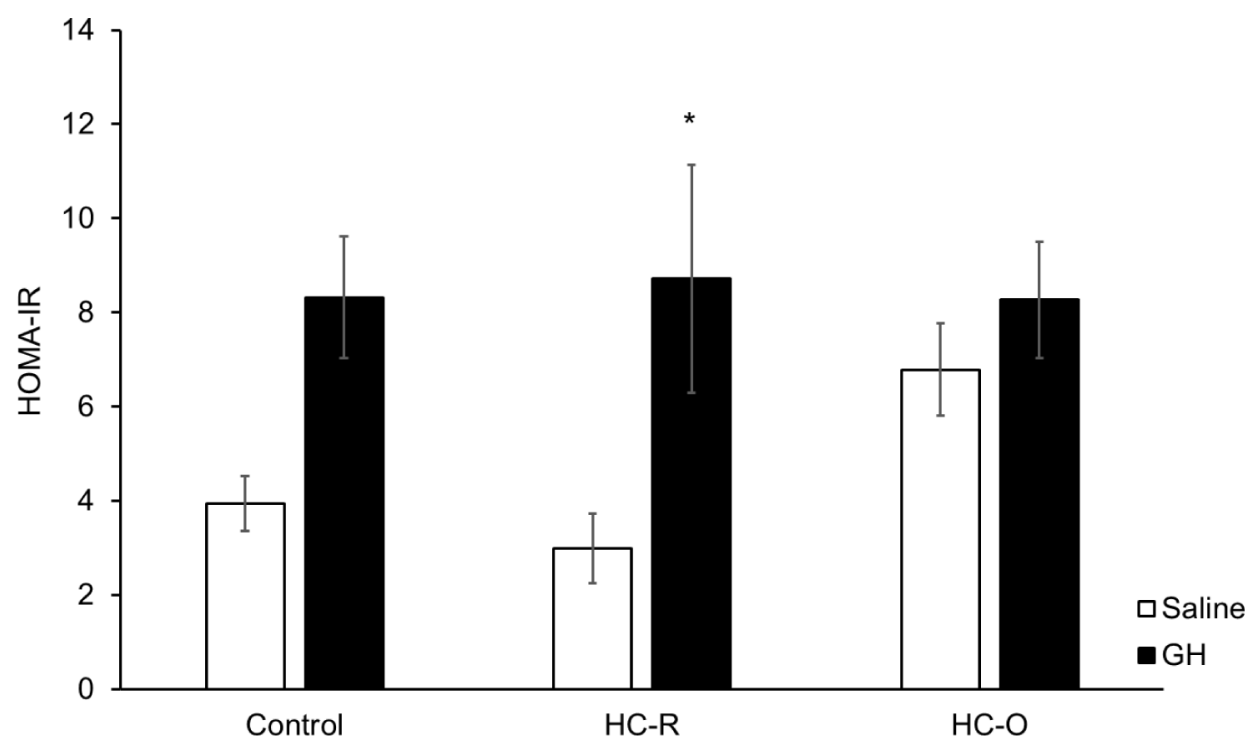

B

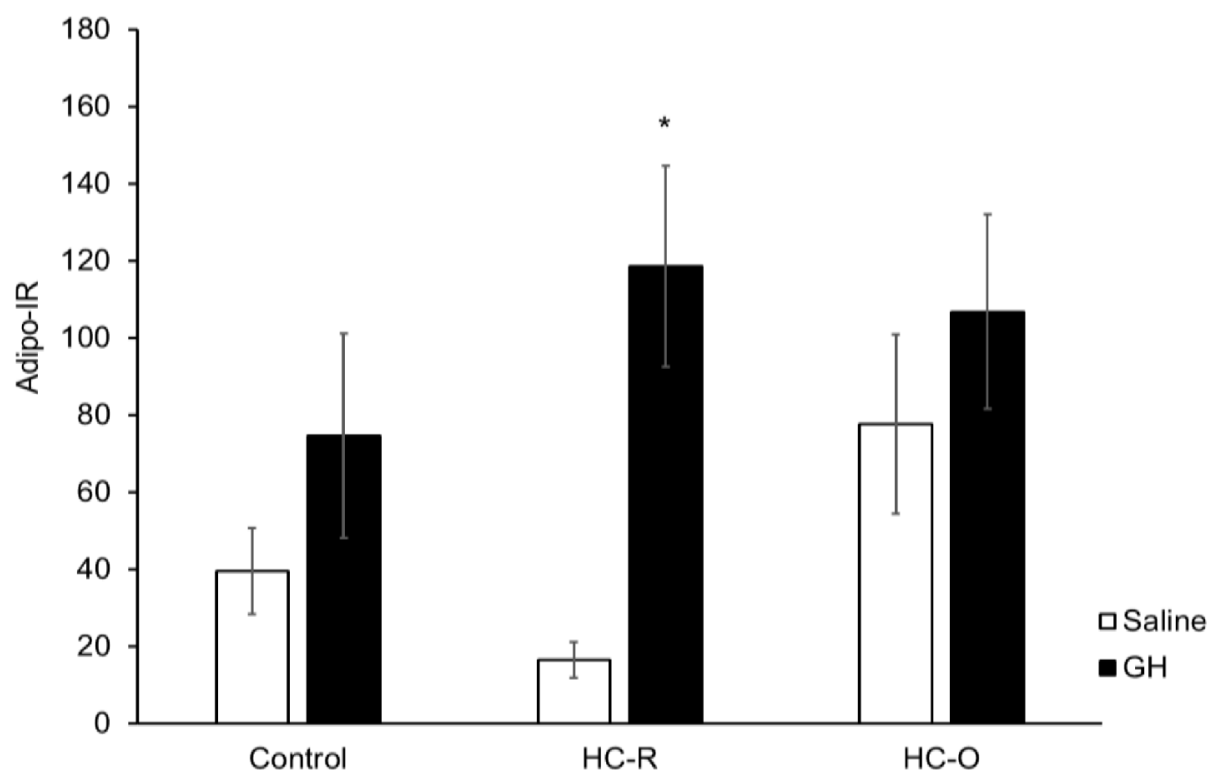

Figure 5. The effect of short-term GH treatment on the surrogate indexes for insulin receptor sensitivity. (A) The calculated HOMA-IR revealed the significant GH effect in HC-R rats. (B) For the Adipo-IR index, GH treatment could increase this index in HC-R rats.

${ }^{*} \mathrm{GH}$ effect is significantly different from saline treatment, $P<0.05$.

Adipo-IR, adipose tissue insulin resistance; GH, growth hormone; HC-R, hypercaloric diet resistance; HOMA-IR, homeostasis model of insulin resistance.

fasting plasma insulin was increased by GH treatment in all rats. However, the short-term GH treatment had no effect on both fasting plasma glucose and FFA. These results suggested that the higher level of plasma insulin is necessary to maintain plasma glucose and FFA during fasting and GH treatment, and these points agree with previous reports $[35,36]$. During the energy deficit of the fasting condition, hepatic glucose output and adipose tissue lipolysis are the major biochemical mechanisms that maintain normal plasma glucose and elevate plasma
FFA [34, 37]. In addition, short-term GH administration increased insulin resistance (IR) via HOMA-IR and Adipo-IR in HC-R rats. Since HOMA-IR and Adipo-IR were the surrogate indexes on IR in different organs, this information suggests that the short-term GH treatment could induce IR in systemic glucose metabolism and adipose tissue lipid metabolism $[35,38]$. However, it is very important at this stage to keep in mind that the current experiment did not measure directly the organ-specific insulin receptor sensitivity. Nevertheless, 
hyperinsulinemia could be able to stimulate leptin secretion from adipose tissue and increase plasma leptin in fasting condition despite the IR [39]. Therefore, the effect of GH on fasting plasma leptin that occurred in the control and HC-R groups apparently mediated in part by insulin-induced leptin secretion. It should be noted that the effect of fasting could promote insulin-mediated glucose uptake [40], which may probably promote leptin secretion.

In conclusion, the current results revealed the short-term effect of GH on plasma leptin levels. GH could decrease basal plasma leptin, which appeared to associate with body adiposity. GH did not produce this effect on meal-induced plasma leptin. In addition, GH could attenuate the fasting effect on plasma leptin.

Author contributions. SL, SK-T, and ST contributed substantially to the conception and design of this study. SL and ST substantially acquired the data and analyzed and interpreted it. SL and ST drafted the manuscript. SK-T critically revised it. All the authors approved the final version submitted for publication and take responsibility for statements made in the published article.

Acknowledgments. We gratefully acknowledge Prof. Thomas A Lutz for his collaboration with laboratory equipment and suggestions on the manuscript. This work was supported by the 100th Anniversary Chulalongkorn University for Doctoral Scholarship (to SL and ST) and by the Special Task Force for Activating Research (STAR \#STF6000231002-1 to ST), Chulalongkorn University.

Conflict of interest statement. The authors have completed and submitted the International Committee of Medical Journal Editors Uniform Disclosure Form for Potential Conflicts of Interest. None of the authors disclose any conflict of interest.

\section{References}

[1] Ahren B, Mansson S, Gingerich RL, Havel PJ. Regulation of plasma leptin in mice: influence of age, high-fat diet, and fasting. Am J Physiol. 1997; 273:R113-20.

[2] Friedman JM, Halaas JL. Leptin and the regulation of body weight in mammals. Nature. 1998; 395:763-70.

[3] Ahren B, Baldwin RM, Havel PJ. Pharmacokinetics of human leptin in mice and rhesus monkeys. Int J Obes Relat Metab Disord. 2000; 24:1579-85.

[4] Bodosi B, Gardi J, Hajdu I, Szentirmai E, Obal F Jr., Krueger JM. Rhythms of ghrelin, leptin, and sleep in rats: effects of the normal diurnal cycle, restricted feeding, and sleep deprivation. Am J Physiol Regul Integr Comp Physiol. 2004; 287:R1071-9.
[5] Sinha MK, Sturis J, Ohannesian J, Magosin S, Stephens T, Heiman ML, et al. Ultradian oscillations of leptin secretion in humans. Biochem Biophys Res Commun. 1996; 228:733-8.

[6] Kalsbeek A, Fliers E, Romijn JA, la Fleur SE, Wortel J, Bakker O, et al. The suprachiasmatic nucleus generates the diurnal changes in plasma leptin levels. Endocrinology. 2001; 142:2677-85.

[7] Mastronardi CA, Walczewska A, Yu WH, Karanth S, Parlow AF, McCann SM. The possible role of prolactin in the circadian rhythm of leptin secretion in male rats. Proc Soc Exp Biol Med. 2000; 224:152-8.

[8] Cammisotto PG, Gelinas Y, Deshaies Y, Bukowiecki LJ. Regulation of leptin secretion from white adipocytes by free fatty acids. Am J Physiol Endocrinol Metab. 2003; 285:E521-6.

[9] Coleman RA, Herrmann TS. Nutritional regulation of leptin in humans. Diabetologia. 1999; 42:639-46.

[10] Langendonk JG, Pijl H, Toornvliet AC, Burggraaf J, Frolich M, Schoemaker RC, et al. Circadian rhythm of plasma leptin levels in upper and lower body obese women: influence of body fat distribution and weight loss. J Clin Endocrinol Metab. 1998; 83:1706-12.

[11] Boni-Schnetzler M, Hauri C, Zapf J. Leptin is suppressed during infusion of recombinant human insulin-like growth factor I (rhIGF I) in normal rats. Diabetologia. 1999; 42:160-6.

[12] Lissett CA, Clayton PE, Shalet SM. The acute leptin response to GH. J Clin Endocrinol Metab. 2001; 86:4412-5.

[13] Leury BJ, Baumgard LH, Block SS, Segoale N, Ehrhardt RA, Rhoads $\mathrm{RP}$, et al. Effect of insulin and growth hormone on plasma leptin in periparturient dairy cows. Am J Physiol Regul Integr Comp Physiol. 2003; 285:R1107-15.

[14] Malmlof K, Din N, Johansen T, Pedersen SB. Growth hormone affects both adiposity and voluntary food intake in old and obese female rats. Eur J Endocrinol. 2002; 146:121-8.

[15] Thammacharoen S, Nguyen T, Suthikai W, Chanchai W, Chanpongsang S, Chaiyabutr N. Somatotropin supplementation decreases feed intake in crossbred dairy goats during the early phase of lactation. Small Ruminant Res. 2014; 121:368-75.

[16] List EO, Palmer AJ, Berryman DE, Bower B, Kelder B, Kopchick JJ. Growth hormone improves body composition, fasting blood glucose, glucose tolerance and liver triacylglycerol in a mouse model of diet-induced obesity and type 2 diabetes. Diabetologia. 2009; 52:1647-55.

[17] Chaiyabutr N, Chanchai W, Sitprija S, Boonsanit D, Thammacharoen $\mathrm{S}$, Chanpongsang S. Interactions of circulating metabolic hormones and metabolites of crossbred holstein cattle in response to supplemental recombinant bovine somatotropin (rbST) and cooling management with misters and fans at different stages of lactation in the tropics. J Anim Vet Adv. 2015; 14:219-31.

[18] Berryman DE, Glad CA, List EO, Johannsson G. The GH/IGF-1 axis in obesity: pathophysiology and therapeutic considerations. Nat Rev Endocrinol. 2013; 9:346-56.

[19] Bray GA, Tartaglia LA. Medicinal strategies in the treatment of obesity. Nature. 2000; 404:672-7.

[20] Campfield LA, Smith FJ, Burn P. Strategies and potential molecular targets for obesity treatment. Science. 1998; 280:1383.

[21] Moller N, Jorgensen JO. Effects of growth hormone on glucose, lipid, and protein metabolism in human subjects. Endocr Rev. 2009; 30:152-77.

[22] Leibowitz SF, Chang GQ, Dourmashkin JT, Yun R, Julien C, Pamy PP. Leptin secretion after a high-fat meal in normal-weight rats: strong 
predictor of long-term body fat accrual on a high-fat diet. Am J Physiol Endocrinol Metab. 2006; 290:E258-67.

[23] Cacho J, Sevillano J, de Castro J, Herrera E, Ramos MP. Validation of simple indexes to assess insulin sensitivity during pregnancy in Wistar and Sprague-Dawley rats. Am J Physiol Endocrinol Metab. 2008; 295:E1269-76.

[24] Lomonaco R, Ortiz-Lopez C, Orsak B, Webb A, Hardies J, Darland $\mathrm{C}$, et al. Effect of adipose tissue insulin resistance on metabolic parameters and liver histology in obese patients with nonalcoholic fatty liver disease. Hepatology. 2012; 55:1389-97.

[25] Malmlof K, Johansen T. Growth hormone-mediated breakdown of body fat: insulin and leptin responses to $\mathrm{GH}$ are modulated by diet composition and caloric intake in old rats. Horm Metab Res. 2003; 35:236-42.

[26] Malmlof K, Fledelius C, Johansen T, Theodorsson E. The anorectic response to growth hormone in obese rats is associated with an increased rate of lipid oxidation and decreased hypothalamic galanin. Physiol Behav. 2011; 102:459-65.

[27] Lee MJ, Wang Y, Ricci MR, Sullivan S, Russell CD, Fried SK. Acute and chronic regulation of leptin synthesis, storage, and secretion by insulin and dexamethasone in human adipose tissue. Am J Physiol Endocrinol Metab. 2007; 292:E858-64.

[28] Levy JR, Lesko J, Krieg RJ Jr., Adler RA, Stevens W. Leptin responses to glucose infusions in obesity-prone rats. Am J Physiol Endocrinol Metab. 2000; 279:E1088-96.

[29] Lee MJ, Fried SK. Multilevel regulation of leptin storage, turnover, and secretion by feeding and insulin in rat adipose tissue. J Lipid Res. 2006; 47:1984-93.

[30] Walker CG, Bryson JM, Bell-Anderson KS, Hancock DP, Denyer GS, Caterson ID. Insulin determines leptin responses during a glucose challenge in fed and fasted rats. Int J Obes. 2005; 29:398-405.
[31] Lee MJ, Fried SK. Integration of hormonal and nutrient signals that regulate leptin synthesis and secretion. Am J Physiol Endocrinol Metab. 2009; 296:E1230-8.

[32] Ahima RS, Prabakaran D, Mantzoros C, Qu D, Lowell B, MaratosFlier E, et al. Role of leptin in the neuroendocrine response to fasting. Nature. 1996; 382:250-2.

[33] Kasuga M, Akanuma Y, Iwamoto Y, Kosaka K. Effects of fasting and refeeding of insulin receptors and glucose metabolism in rat adipocytes. Endocrinology. 1977; 100:1384-90.

[34] Duncan RE, Ahmadian M, Jaworski K, Sarkadi-Nagy E, Sul HS. Regulation of lipolysis in adipocytes. Annu Rev Nutr. 2007; 27:79-101.

[35] Hettiarachchi M, Watkinson A, Jenkins AB, Theos V, Ho KK, Kraegen EW. Growth hormone-induced insulin resistance and its relationship to lipid availability in the rat. Diabetes. 1996; 45:415-21.

[36] Thirone AC, Carvalho CR, Brenelli SL, Velloso LA, Saad MJ. Effect of chronic growth hormone treatment on insulin signal transduction in rat tissues. Mol Cell Endocrinol. 1997; 130:33-42.

[37] Petersen MC, Vatner DF, Shulman GI. Regulation of hepatic glucose metabolism in health and disease. Nat Rev Endocrinol. 2017; 13:572-87.

[38] Kahn BB, Flier JS. Obesity and insulin resistance. J Clin Invest. 2000; 106:473-81.

[39] Wang J, Liu R, Hawkins M, Barzilai N, Rossetti L. A nutrient-sensing pathway regulates leptin gene expression in muscle and fat. Nature. $1998 ; 393: 684-8$.

[40] Halberg N, Henriksen M, Soderhamn N, Stallknecht B, Ploug T, Schjerling P, et al. Effect of intermittent fasting and refeeding on insulin action in healthy men. J Appl Physiol. 2005; 99:2128-36. 